\title{
Certificação florestal na visão gerencial e estratégica da indústria moveleira nacional ${ }^{1}$
}

\section{Forest certification in the managemental and strategical vision of the national furniture industry}

\author{
Laércio Antônio Gonçalves Jacovine ${ }^{2}$; Ricardo Ribeiro Alves ${ }^{3 *}$; \\ Sebastião Renato Valverde ${ }^{4}$; Márcio Lopes da Silva ${ }^{4}$
}

\section{Resumo}

O presente estudo teve como objetivo avaliar a contribuição da certificação florestal na visão gerencial e estratégica das empresas moveleiras nacionais certificadas. Para realizar o estudo aplicou-se um questionário nas empresas certificadas da indústria moveleira. Verificou-se que a certificação representa um fator de importância no processo de exportação destas empresas. Ela proporciona, também, uma melhoria de sua imagem perante o mercado consumidor e está inserida em seu planejamento estratégico. Conclui-se que a certificação florestal está crescendo na indústria moveleira nacional e representando um fator de competitividade para exportação. A melhoria de imagem proporcionada representa a maior vantagem obtida por estas empresas. Pode-se concluir, também, que a principal razão de se buscar a certificação florestal, na indústria moveleira, é a demanda do mercado, que atualmente tem sido principalmente do mercado externo.

Palavras-chave: Mercado moveleiro, cadeia de custódia, exportação.

\begin{abstract}
The present study had as objective to evaluate the contribution of the forest certification in the managemental and strategical vision of the certified national furniture companies. A questionnaire was applied in the certified companies of the industry. It was verified that this certification consists in a factor of importance in the process of exportation of the companies. It provides, also, an improvement of its image before the consuming market and is inserted in its strategical planning. The conclusion is that the forest certification is growing in the national furniture industry and represents a factor of competitiveness for exportation. The improvement of image represents the biggest advantage gotten for these companies. It can be concluded, also, that the main reason of searching the forest certification in this industry is the demand of the market mainly from the external one.
\end{abstract}

Key words: Furniture market, chain-of-custody, exportation.

1 Parte da dissertação de mestrado em Ciência Florestal do segundo autor - UFV. Pesquisa financiada pela Fundação de Amparo à Pesquisa do Estado de Minas Gerais (FAPEMIG).

2 Professor Adjunto do Departamento de Engenharia Florestal - Universidade Federal de Viçosa (UFV) - jacovine@ ufv.br.

3 Bacharel em Administração e Doutorando em Ciência Florestal - Departamento de Engenharia Florestal - Universidade Federal de Viçosa (UFV) - ricardo@ vicosa.ufv.br> Professor da Faculdade Ubaense Governador Ozanam Coelho (FAGOC) - Ubá-MG.

${ }^{4}$ Professore Adjunto do Departamento de Engenharia Florestal - Universidade Federal de Viçosa (UFV).

* Autor para correspondência 


\section{Introdução}

A maior conscientização dos consumidores com relação às questões ambientais e sociais tem levado as empresas, no geral, a adotarem uma postura diferente no mercado buscando minimizar os impactos ao meio ambiente e respeitar o trabalho humano. Em alguns mercados nacionais esta postura positiva pode se transformar num diferencial e suas empresas conseguirem obter vantagens nos negócios, tais como, melhoria da imagem institucional, por exemplo.

De acordo com Coutinho e Soares (2002), as empresas brasileiras estão seguindo uma tendência mundial de preocupação com a responsabilidade social. Sendo assim, passam a contemplar mudanças organizacionais de implicações estratégicas profundas. Parte-se da premissa de que, para serem efetivas, tais mudanças devem estar alinhadas com a estratégia de negócios da empresa.

Além das questões sociais, segundo Venzke (2002), a preocupação com as questões ambientais tem levado as empresas a desenvolverem programas de prevenção e redução de impacto ambiental, visando atender às exigências dos consumidores, bem como também à legislação cada vez mais restritivas.

Para atender a estas questões sociais e ambientais exigidas pela sociedade Nardelli e Griffith (2003a) destacaram que as empresas devem promover uma mudança de seus valores empresariais que irão guiar suas futuras estratégias, conscientizando-se que o meio ambiente e o fator humano devem ser respeitados.

No caso de produtos de origem florestal um dos mecanismos encontrados para amenizar tais questões é a certificação florestal. Além disso, como afirmaram Nardelli e Tomé (2002), as empresas certificadas se diferenciam no mercado contribuindo para eliminar alguns segmentos do setor que se fundamentam na ilegalidade e em custos ambientais e sociais inadmissíveis.

Desta forma, a certificação florestal surge, justamente, como uma alternativa encontrada, pois, segundo Nardelli (2001), em vez de prejudicar toda uma classe de produtos, foram propostos o reconhecimento e o consumo de produtos florestais produzidos sob um manejo adequado.

O primeiro sistema de certificação florestal, o FSC - Forest Stewardship Council (Conselho de Manejo Florestal) foi fundado em 1993. O FSC é uma ONG fundada em 1993 e foi criada com o intuito de harmonizar o processo de certificação florestal.

Sobre o FSC, Nardelli e Griffith (2003b) ressaltaram que é uma organização internacional independente, formada por representantes do movimento ambiental, pesquisadores, produtores de madeira, comerciantes de produtos florestais e populações tradicionais e, atualmente, com sede na Alemanha.

De acordo com o Instituto de Manejo e Certificação Florestal e Agrícola (2002), existem duas modalidades de certificação implementadas pelos órgãos credenciados pelo FSC: a certificação do manejo florestal, a qual certifica operações de manejo florestal que cumprem com o princípios e critérios do FSC, e a certificação de cadeia de custódia (CoC), a qual certifica as indústrias que processam e vendem produtos florestais, rastreando a matéria-prima desde a floresta até o consumidor. Em ambos os casos, ressaltou Suiter Filho (2000), a certificação não se aplica ao proprietário ou à empresa, e, sim, à unidade de manejo florestal ou ao produto determinado.

Todavia, o interesse em se entrar num processo visando à obtenção da certificação florestal em uma empresa, surge com a tomada de decisão de sua alta direção, composta por proprietários, sócios e diretores. Deve-se analisar os prós e contras de tal decisão que implica não somente em gastos financeiros, mas também de envolvimento de recursos humanos e de tempo despendido. Ao se tomar, entretanto, a decisão pela certificação, os envolvidos precisam estar cientes dos passos a serem tomados referentes ao processo em si, dos custos diretos e indiretos e da continuidade de se seguir os 
padrões após a obtenção do certificado, visando sua manutenção.

Dentre os setores de base florestal que tem buscado este tipo de certificação encontra-se a indústria moveleira, através de algumas empresas, conforme estudo de Alves (2005). Desta forma, fazse necessário entender o que a certificação florestal representa para estas empresas certificadas em termos gerenciais e estratégicos.

Sendo assim, o presente estudo teve como objetivo geral avaliar como é a visão gerencial e estratégica da indústria moveleira nacional, particularmente de empresas certificadas em cadeia de custódia. Como objetivos específicos buscou-se:

- verificar a importância da certificação florestal nas estratégias de vendas, na visão gerencial e estratégica;

- verificar alterações relacionadas aos aspectos ambientais e sociais promovidos pela certificação de cadeia de custódia;

- verificar as principais mudanças em termos de controle para se obter a certificaçao;

- verificar o envolvimento da certificação florestal no planejamento estratégico da empresa;

- verificar a contribuição da certificação para o "marketing" destas empresas;

- conhecer os principais benefícios da certificação de cadeia de custódia, junto às empresas moveleiras certificadas.

\section{Material e Métodos}

Delimitação das empresas moveleiras certificadas no Brasil

No Brasil existem dois sistemas de certificação: o Conselho de Manejo Florestal (Forest Stewardship Council - FSC), de iniciativa internacional, e o Sistema Brasileiro de Certificação Florestal (CERFLOR), de iniciativa brasileira. O CERFLOR reúne a Associação Brasileira de Normas Técnicas
(ABNT), o Instituto Nacional de Metrologia (INMETRO) e a Sociedade Brasileira de Silvicultura (SBS).

Tanto o FSC quanto o CERFLOR já estavam aptos a certificar tanto pelo manejo florestal quanto pela cadeia de custódia. $\mathrm{Na}$ época, porém, apenas o FSC possuía empresas com produtos certificados. Para se delimitar as empresas moveleiras nacionais com certificado de cadeia de custódia, buscaram-se apenas os dados existentes no FSC.

Em dezembro de 2004, existiam 169 empresas com produtos certificados de cadeia de custódia. Para se chegar aos números da indústria moveleira, delimitou-se empresas cujo produto certificado (escopo da certificação) fosse "móveis". Obteve-se um total de 28 empresas.

\section{Coleta de dados}

Para obter os dados desta pesquisa optou-se pela aplicação de um questionário (Apêndice A), enviando-o inicialmente pelo correio. Para Cervo e Bervian (2002), o questionário deve conter um conjunto de questões, logicamente relacionadas com um problema central, e pode ser enviado pelo correio, entregue ao respondente ou aplicado por elementos preparados e selecionados.

Antes do envio do questionário pelo correio realizou-se uma adequação do mesmo através da análise por profissionais com experiência no assunto.

\section{Envio do questionário para as empresas moveleiras certificadas}

Nos dados consultados junto ao FSC existiam, além do nome da empresa e a relação dos produtos certificados da mesma, o nome do profissional de contato para certificação florestal, com seu respectivo telefone e endereço eletrônico. As formas adotadas para envio e obtenção das respostas aos questionários foram: correios postal e eletrônico, e contato telefônico. 
Das 28 empresas, 10 foram desconsideradas da pesquisa pelos seguintes motivos:

- duas, por não possuir mais a certificação florestal e, portanto, não atendiam mais aos critérios adotados pela pesquisa;

- uma, por atuar como prestadora de serviços na área de design e não possuir processo produtivo;

- sete, por não se conseguir estabelecer nenhuma forma de contato.

Ao final, das 18 empresas contatadas, nove responderam ao questionário, correspondendo a 50\% do total, o que pode ser considerado um percentual de resposta que representa a população pesquisada.

\section{Análise dos dados e apresentação dos resultados}

Os dados referentes às respostas do questionário foram organizados e sistematizados por meio de tabulação, utilizando-se planilha eletrônica. Seus resultados estão apresentados na forma de gráficos, quadros ou texto.

\section{Resultados e Discussão}

Os resultados serão apresentados, e discutidos, conforme a seqüência apresentada nos objetivos específicos mencionados anteriormente.

\section{A certificação florestal como estratégia de vendas}

Inicialmente procurou-se abordar qual o grau de importância desta certificação na estratégia de vendas das empresas pesquisadas. Por meio dos resultados obtidos, verificou-se que, para $78 \%$ das empresas, a certificação florestal é considerada importante para alavancar vendas, conquistar novos mercados (principalmente o externo) e novos clientes.

Dentre as $\mathbf{7 8 \%}$ das empresas que consideram a certificação importante para alavancar vendas, conquistar novos mercados e novos clientes, $42,85 \%$ a mencionam como uma das principais estratégias, $42,85 \%$ uma estratégia secundária e 14,3\%, como a principal estratégia. Neste último caso, alegou-se que, sem a certificação, não se poderia entrar em determinado mercado, sendo destacado, principalmente, o mercado europeu.

Dentre os 22\% das empresas que não consideram uma estratégia importante, $50 \%$ diz que se trata apenas de uma exigência do mercado enquanto a outra metade respondeu que foi apenas uma opção da empresa, não sendo mencionada a razão específica para tal investimento.

Desta forma, a certificação florestal provoca um impacto nas decisões gerenciais e estratégicas destas empresas. Além disso, conforme ressaltou Nardelli (2001), para algumas empresas, a adoção dos padrões pode oferecer uma oportunidade de melhorar continuamente suas atividades, a confiabilidade de seus produtos ou serviços e a qualidade de suas relações com seus clientes, empregados e com a comunidade, o que reflete positivamente em sua lucratividade.

\section{A certificação florestal e as transformações sociais e ambientais}

A obtenção da certificação de cadeia de custódia para um produto exige a rastreabilidade da matériaprima certificada em todo o processo industrial, desde a entrada da mesma até a confecção do produto final. Espera-se, no entanto, que uma empresa, que venha a obter certificação florestal possua conduta social e ambiental responsável. Procurou-se, assim, verificar em quais aspectos sociais e ambientais estas empresas promoveram mudanças, mesmo não sendo uma exigência atualmente explícita da certificação.

Das empresas que responderam ao questionário, apenas $22 \%$ promoveram algum tipo de alteração nos aspectos sociais relacionados aos seus funcionários. Dentre as principais alterações, após a certificação, a implantação de ensino supletivo (médio e fundamental) e alfabetização de jovens e adultos 
na empresa, oportunizando uma qualificação para todos os seus colaboradores. Uma das empresas afirmou que a busca da certificação foi precedida da preocupação social e relatou:

acreditamos que o homem é parte integrante do meio ambiente e de nada vale a preservação ou exploração controlada da natureza se a preocupação social for deixada de lado. Certificação e respeito aos aspectos sociais devem caminhar alinhados, pois de que adiantaria uma empresa certificada explorar o trabalho escravo?

Com relação às mudanças em aspectos ambientais, ela foi promovida apenas em 33\% das empresas pesquisadas. Estas alterações estiveram mais relacionadas com a maior conscientização dos colaboradores através de treinamentos, palestras e reciclagem de resíduos.

Estas variações, entre empresas que promoveram mudanças ambientais e sociais e entre empresas que não as promoveram, podem ser atribuídas às diferenças em valores e estratégias gerenciais, conforme destacaram Nardelli e Griffith (2003b). Segundo os mesmos autores, existe uma grande variação na extensão pela qual as empresas assumem sua responsabilidade ambiental e social e a incorporam em suas políticas e operações.

Sobre a questão da não exigência atual da verificação de aspectos sociais e ambientais nas operações certificadas em cadeia de custódia, de acordo com o Instituto de Manejo e Certificação Florestal e Agrícola (2002), a sociedade questiona o fato delas não terem este desempenho avaliado, sendo que incentivam e ratificam tais análises na floresta quando consomem materiais certificados. Há, no entanto, uma tendência de incorporação dessas questões num futuro próximo.

\section{O controle dos processos nas empresas certificadas}

Em relação aos controles, procurou-se identificar quais foram as principais mudanças efetuadas pelas empresas no processo de certificação. Os resultados encontrados foram os seguintes:

a) $77 \%$ das empresas revelaram que fazem o controle da matéria-prima certificada na entrada, no processamento e na saída. Este controle está relacionado a rastreabilidade física da matériaprima certificada, existindo uma preocupação em não se misturar material certificado com nãocertificado, de maneira a não comprometer à porcentagem exigida no produto final.

b) $66 \%$ das empresas revelaram efetuar o controle dos documentos em todas as etapas da cadeia de custódia. Este controle serve para comprovar a origem do material certificado. Além da comprovação na origem (que pode ser uma nota fiscal do fornecedor da matéria-prima), a cada etapa controla-se o material que deu entrada ou saída de uma unidade de produção, através de documentos e, com o produto final, sua comprovação através de notas fiscais de venda.

c) $66 \%$ das empresas revelaram que fazem o controle e garantem que apenas produtos certificados sejam identificados como certificado ou etiquetados com a logomarca FSC.

d) $66 \%$ das empresas mencionaram a importância da manutenção de registros de todos os ingressos, processamentos e saídas de produtos certificados, a fim de se manter a rastreabilidade. Todos os registros devem ser mantidos e arquivados para futura inspeção, caso seja necessário.

e) $33 \%$ destas empresas revelaram a necessidade da especificação das pessoas responsáveis pelo controle. Estas pessoas seriam as responsáveis pelo acompanhamento da produção, a fim de se garantir a porcentagem exigida de material certificado no produto final.

f) $33 \%$ das empresas destacaram a comprovação, através de faturas, que identifiquem a procedência certificada da matéria-prima. Esta necessidade deve-se ao fato de que toda matéria-prima certificada deve chegar à empresa devidamente documentada e mencionando seu número de registro da certificação. 
Pelos resultados apresentados, verifica-se que as grandes mudanças, em termos de controle, estiveram relacionadas à chegada, processamento e saída da matéria-prima certificada. Este fato sugere que os maiores investimentos feitos pelas empresas podem ter sido neste tipo de controle. Dentre estes investimentos pode-se citar, principalmente, a capacitação da mão-de-obra e a demarcação de espaço físico para material certificado e nãocertificado.

\section{A certificação florestal no planejamento estratégico}

Pelo fato da certificação florestal constituir-se numa decisão que envolve a alta direção da empresa, torna-se necessário verificar como a mesma se relaciona com o planejamento estratégico da empresa, como um todo. Neste sentido, procurou-se abordar quais as principais mudanças provocadas pela certificação florestal nas empresas moveleiras certificadas, em termos de planejamento estratégico. As respostas obtidas foram as seguintes:

a) $55 \%$ das empresas revelaram a importância da utilização da certificação florestal em propagandas institucionais. Como esta certificação pode se tornar um diferencial para a empresa que a adota, torna-se oportuno divulgá-la aos consumidores.

b) $55 \%$ das empresas destacaram como importante a inclusão da certificação florestal na missão e política da empresa. A certificação florestal, mais que um simples certificado, pode se tornar num instrumento de mudanças no ambiente empresarial. Outros processos da empresa, alheios à certificação, podem ser favorecidos. Além disso, questões como maior conscientização ambiental de seus funcionários podem ser incentivadas. Sendo assim, a certificação pode assumir um caráter mais amplo e fazer parte da missão ou política de uma empresa. c) Para $44 \%$ das empresas torna-se necessário um maior envolvimento do responsável pela certificação nas decisões estratégicas da empresa. Como a certificação pode assumir um papel de principal impulsionadora na alavancagem das vendas de uma empresa, o funcionário responsável pela mesma pode representar um importante elemento na condução dos negócios e, muitas vezes, participar de decisões mais amplas, pois ocupa um cargo estratégico.

d) $33 \%$ das empresas destacaram a importância do uso da experiência adquirida com o controle implementado com a certificação, em outras áreas da empresa, em função da mudança da cultura organizacional.

De acordo com o exposto, verifica-se que algumas das empresas que responderam à pesquisa optaram numa inclusão mais próxima do responsável pela certificação florestal em suas decisões estratégicas enquanto que outras o deixam num nível mais inferior em termos de decisão.

\section{A certificação florestal e o "marketing" das empresas}

A empresa que adota a certificação de cadeia de custódia pretende informar ao consumidor que seu produto utiliza matéria-prima certificada oriunda de florestas que utilizaram um manejo considerado adequado, ou seja, com mínimos impactos sociais e ambientais. Neste sentido, buscou-se verificar em quais aspectos a certificação florestal contribuiu para o "marketing" da empresa, dando ênfase aos chamados 4 P's (produto, preço, praça - logística, promoção - propaganda) ou mix de marketing, conforme Kotler e Armstrong (1998).

Os resultados mostraram que, em termos de marketing, a maioria das empresas pesquisadas consideram que os maiores ganhos estiveram relacionados com a melhoria da imagem da empresa (Figura 1). 


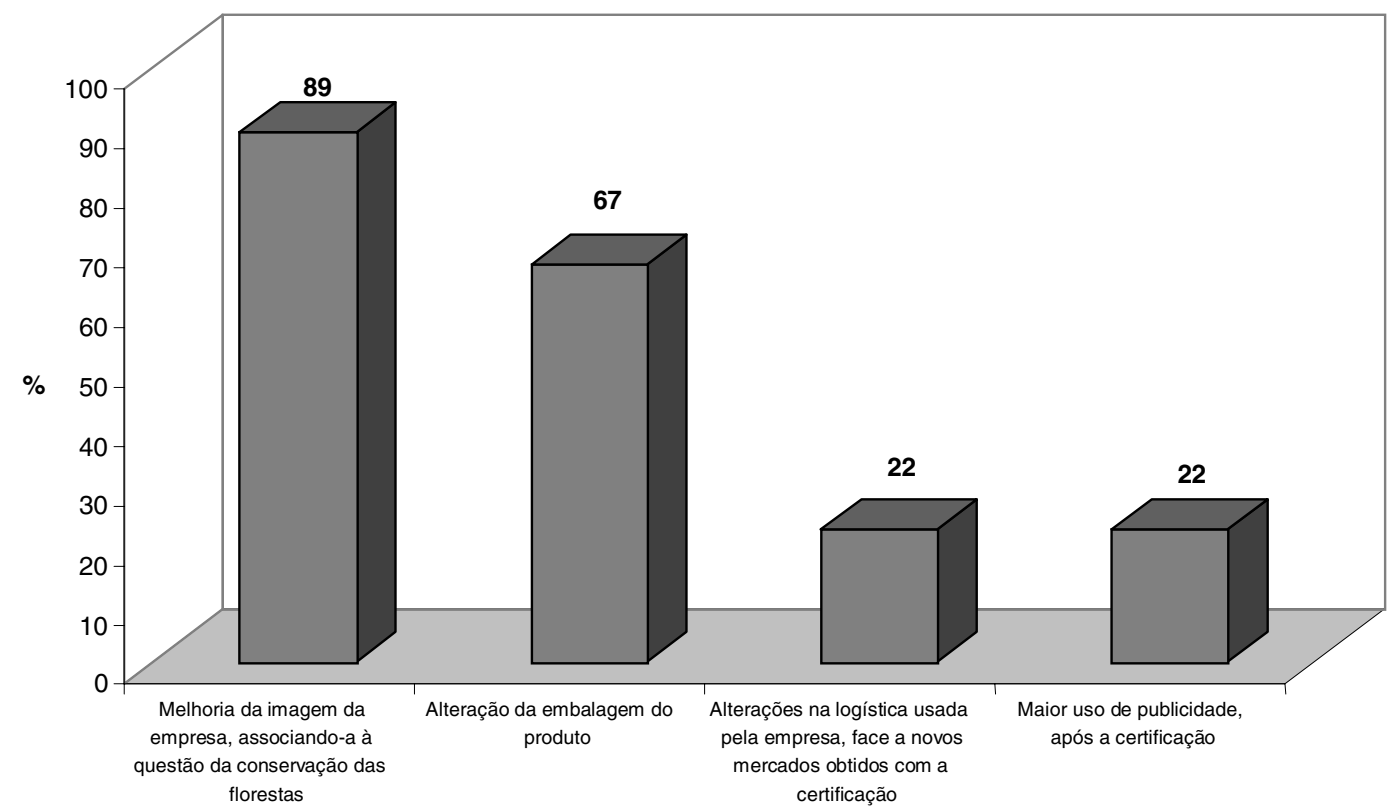

Figura 1. Principais aspectos em que a certificação florestal contribuiu no marketing das empresas pesquisadas, em $\%$.

Outros aspectos que provocaram modificações no marketing das empresas, devido à certificação, conforme a Figura 1, foram os seguintes:

a) Promoção de alterações na embalagem de seus produtos (67\%). Tais alterações estão relacionadas ao fato de que a embalagem dos produtos certificados deve estar identificada como tal e, além disso, não poderá conter em seu interior produtos não certificados;

b) Promoção de alterações na logística usada pela empresa (22\%). Com a certificação florestal, muitas das empresas alcançaram novos mercados e precisaram redefinir sua logística.

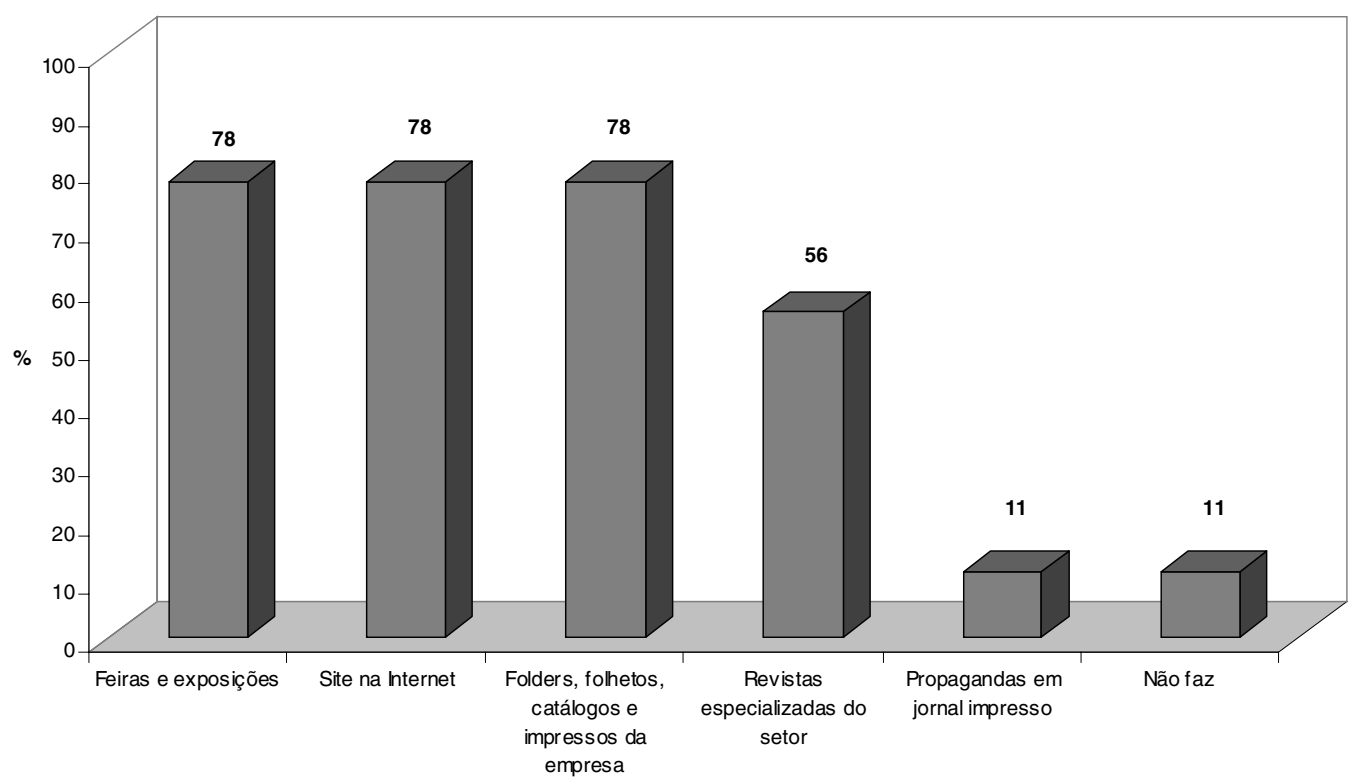

Figura 2. Principais formas de divulgação da certificação florestal mencionadas pelas empresas pesquisadas, em \%. 
c) Ocorrência de maior uso de publicidade após a certificação (22\%). Sobre esta questão de divulgação da certificação, Donaire (1999) citou que, uma vez engajada na intenção de melhorar e manter sua imagem ambiental, a empresa deve, além de implementar medidas efetivas para a preservação, desenvolver programas mais amplos que incluem: programar visitas às fábricas, organizar mesasredondas e informativos sobre o assunto, estabelecer ligações com os órgãos de controle, imprensa e grupos ambientalistas e propiciar programas de informações ambientais para os diferentes segmentos da comunidade. Deste modo, verificou-se que as principais formas de divulgação da certificação florestal adotadas pelas empresas certificadas foram: feiras, exposições, sites e impressos (Figura 2).

A divulgação da certificação de produtos de uma empresa por meio de feiras e exposições, visa atingir a um número grande de atores que circulam nas mesmas, como: consumidores nacionais e internacionais, fornecedores, revendedores, representantes de vendas, representantes de órgãos públicos, de órgãos ambientais, seguradoras, bancos, organizações não-governamentais, dentre outros.

No caso da divulgação em site, o princípio é o mesmo: faz-se necessário, no entanto, que o usuário tenha conhecimento do endereço eletrônico da empresa, na Internet. A divulgação relacionada aos impressos da empresa (como folders, folhetos e catálogos), em geral, pode estar associada a uma feira ou exposição que a mesma participe.

Divulgação em revistas especializadas na indústria moveleira ou jornal impresso tem, como fator limitante, o fato de atingirem um menor número de pessoas. Por outro lado, este público, geralmente, já possui um maior conhecimento sobre o assunto.

\section{Benefícios obtidos com a certificação florestal}

O principal objetivo de uma empresa que obtém a certificação florestal é conseguir, em seu mercado, benefícios advindos da mesma. Isto porque a empresa somente buscará esta certificação se seus dirigentes concluírem que a mesma trará algum retorno. Desta forma, procurou-se saber qual foi a principal vantagem obtida por elas, em razão da adoção da certificação.

De acordo com os resultados obtidos, verificouse que a maioria das empresas que responderam à pesquisa considera, como maior vantagem a melhoria de sua imagem institucional (Figura 3).

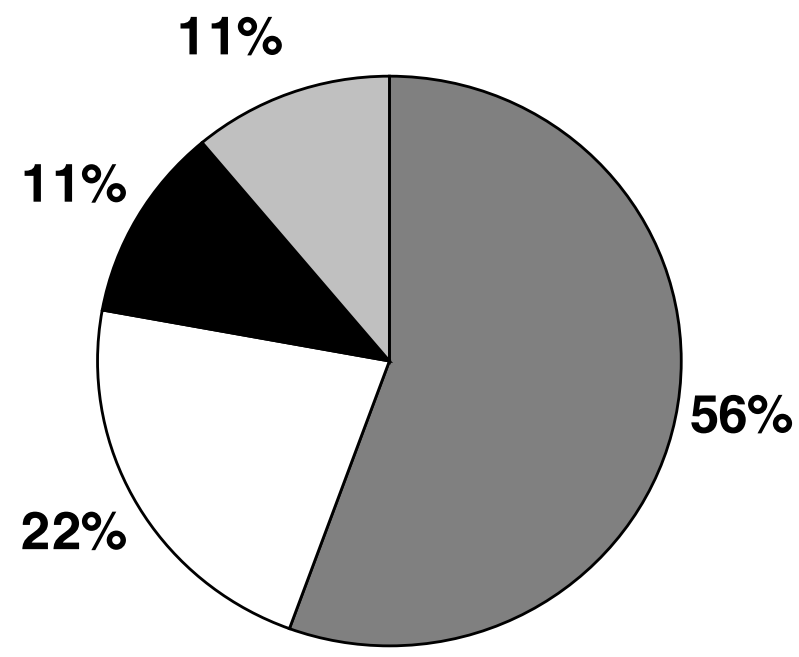

$\square$ Melhoria da imagem institucional da empresa

$\square$ Abertura/Manutenção do mercado

- Aumento da demanda

Ainda não utilizam

Figura 3. Principal vantagem alcançada com a certificação florestal, nas empresas pesquisadas 
Sendo assim, a melhoria da imagem empresarial, além de representar a maior contribuição, em termos de "marketing" para estas empresas, como mencionado anteriormente, também se configura na maior vantagem adquirida. Obter uma certificação de cadeia de custódia, na indústria moveleira, pode significar diferenciar-se dos demais através de uma imagem empresarial que reforce os compromissos ambientais e sociais da empresa perante a sociedade.

Verifica-se, pela Figura 3, que a abertura ou manutenção do mercado foram citados por apenas $22 \%$ das empresas. Sendo assim, para a indústria moveleira, atualmente, a certificação florestal não se mostra tão decisiva para atingir novos mercados ou mantê-los. Dentre as razões para este resultado pode-se citar o destino dado aos produtos destas empresas que, em muitos casos, são enviados para países não sensíveis à certificação.

Além destes benefícios diretos, devem-se ressaltar outros indiretos que muitas vezes não são quantificados e que são obtidos no processo da certificação. Existem outras vantagens advindas, como por exemplo, redução de custo e a elevação da qualidade e produtividade das indústrias, e que contribuem na busca da competitividade internacional, conforme relatado por Silva e Bravo (1994).

\section{Conclusões}

Pelos resultados apresentados neste trabalho, pode-se concluir que:
- a certificação florestal, nas empresas pesquisadas, constitui-se num dos principais fatores de incremento em vendas;

- as alterações ambientais e sociais provocadas com a certificação de cadeia de custódia foram reduzidas, já que poucas empresas pesquisadas promoveram algum tipo de modificação nos seus processos, relacionados a estas questões;

- as principais mudanças efetuadas pelas empresas, em termos de controle, foi com relação a matériaprima certificada na entrada, no processamento e na saída;

- em termos de planejamento estratégico, para a maioria das empresas pesquisadas, a certificação florestal passa a figurar em sua missão e política, além de ser um instrumento importante em propagandas institucionais;

- apesar das empresas pesquisadas considerarem que a certificação florestal é importante no incremento nas vendas, verifica-se que, para elas, a maior vantagem obtida está relacionada com a melhoria de sua imagem institucional;

- a melhoria da imagem institucional, advinda da certificação florestal, também é apontada como a principal contribuição para o "marketing" destas empresas;

- a certificação florestal é um mecanismo importante na visão gerencial e estratégica das empresas pesquisadas, principalmente no que se refere ao aumento da competitividade da indústria moveleira. 


\section{APÊNDICE A}

Questionário aplicado nas empresas moveleiras com certificação florestal

1- A certificação é considerada como uma importante estratégia para alavancar vendas, conquistar novos mercados e novos clientes?
( ) $\mathrm{Sim}$
( ) Não

a) Se sim, responda:
( ) É a principal estratégia
( ) É uma das principais estratégias utilizadas
( ) É uma das estratégias mas é secundária
( ) Outros. Especificar:

b) $\underline{\text { Se não, responda: }}$
( ) É apenas uma exigência do mercado
( ) Foi apenas uma opção da empresa
( ) Outros. Especificar:

2- A empresa promoveu alterações nos aspectos sociais relacionados aos seus funcionários, em função da certificação da cadeia de custódia, mesmo não sendo uma exigência explícita desta?
( ) $\operatorname{Sim}$
( ) Não

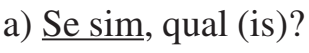

3- A empresa promoveu alterações nos aspectos ambientais em função da certificação de cadeia de custódia, mesmo não sendo uma exigência explícita desta?
( ) $\mathrm{Sim}$
( ) Não

a) Se sim, qual (is)?

4- Para a obtenção da certificação de cadeia de custódia, quais foram as principais mudanças em termos de CONTROLE que a empresa teve que passar? (marcar no máximo três opções)

( ) Controle dos documentos em todas as etapas da cadeia de custódia

( ) Especificar as pessoas que estariam responsáveis pelo controle

( ) Controle da matéria-prima certificada na entrada, no processamento e na saída.

( ) Controle que garante que apenas produtos certificados sejam identificados como certificado ou etiquetados com o nome FSC

( ) Comprovação através de faturas que identifiquem a procedência certificada

( ) Manutenção de registros de todos os ingressos, processamentos e saídas de produtos certificados, a fim de se manter a rastreabilidade.

( ) Outras. Especificar: 
5- Quais foram as mudanças mais significativas, em termos de PLANEJAMENTO ESTRATÉGICO, com a certificação de cadeia de custódia? (marcar no máximo três opções)

( ) Envolvimento do responsável pela certificação nas decisões estratégicas da empresa

( ) Inclusão da certificação florestal na missão/política da empresa

( ) Uso da filosofia de controle em outras áreas da empresa, em função da mudança da cultura organizacional, promovida com a implementação dos controles exigidos pela certificação

( ) Redefinição de políticas de cargos e salários devido à certificação

( ) Utilização da certificação em propagandas institucionais

( ) Outras. Especificar:

6- Em quais aspectos principais a Certificação Florestal contribuiu para o MARKETING da empresa, dando ênfase aos chamados 4 P's (produto, preço, praça - logística, promoção - propaganda), mix de marketing? (marcar no máximo quatro opções)

( ) Redefinições no layout do produto

( ) Redefinições da funcionalidade do produto

( ) Alteração da embalagem do produto

( ) Obtenção de sobre-preço em função da valorização do produto

( ) Acréscimo no preço do produto em função dos gastos incorridos na certificação

( ) Alterações na logística usada pela empresa, face a novos mercados obtidos com a certificação

( ) Maior uso de publicidade, após a certificação

( ) Melhoria da imagem da empresa, associando-a a questão da conservação das florestas

( ) Outras. Especificar:

7- Em quais destas situações a empresa normalmente divulga o fato de ter seus produtos certificados (podese marcar mais de uma opção).

( ) Feiras e exposições

( ) Propagandas em TV

( ) Propagandas em rádio

( ) Propagandas em jornal impresso

( ) Site na Internet

( ) Folders, folhetos, catálogos e impressos da empresa

( ) Revistas especializadas do setor

( ) Outros. Especificar:

( ) Não faz

8- Qual foi a maior vantagem obtida com a certificação? (marcar apenas uma opção)

( ) Obtenção de "Sobre-preço"

( ) Melhoria do relacionamento com os órgãos governamentais, sindicatos, etc

( ) Melhoria da imagem institucional da empresa

( ) Abertura/Manutenção do mercado

( ) Redução de custos

( ) Aumento da demanda

( ) Outros. Especificar:

9- Espaço destinado para considerações adicionais que a empresa deseja fazer a respeito da certificação florestal elou do presente trabalho. 


\section{Referências}

ALVES, R. R. A certificação florestal na indústria moveleira nacional com ênfase no Pólo de Ubá, MG. 2005. Dissertação (Mestrado em Ciência Florestal) Universidade Federal de Viçosa, Viçosa.

CERVO, A. L.; BERVIAN, P. A. Metodologia científica. 5. ed. São Paulo: Prentice Hall, 2002.

COUTINHO, R. B. G.; SOARES, T. D. L. A. M. Gestão estratégica com responsabilidade social: arcabouço analítico para auxiliar sua implementação nas empresas no Brasil. Revista de Administração Contemporânea, Curitiba, v.6, n.3, p.75-96, 2002.

DONAIRE, D. Gestão ambiental na empresa. São Paulo: Atlas, 1999. $169 \mathrm{p}$.

INSTITUTO DE MANEJO E CERTIFICAÇÃO FLORESTAL E AGRÍCOLA (IMAFLORA). Manual de certificação de cadeia de custódia no sistema do Forest Stewardship Council - FSC. Piracicaba: IMAFLORA, 2002.

KOTLER, P.; ARMSTRONG, G. Princípios de Marketing. Rio de Janeiro: Prentice-Hall, 1998.

NARDELLI, A. M. B. Sistemas de certificação e visão de sustentabilidade no setor florestal brasileiro. 2001. Tese (Doutorado em Ciência Florestal) - Universidade Federal de Viçosa, Viçosa.
NARDELLI, A. M. B.; GRIFFITH, J. J. Mapeamento conceitual da visão de sustentabilidade de diferentes atores do setor florestal brasileiro. Revista Árvore, Viçosa, v.27, n.2, p.241-256, 2003a.

NARDELLI, A. M. B.; GRIFFITH, J. J. Modelo teórico para compreensão do ambientalismo empresarial do setor florestal brasileiro. Revista Árvore, Viçosa, v.27, n.6, p.855$869,2003 b$.

NARDELLI, A. M. B.; TOMÉ, M. V. D. F. Efeito multiplicador dos benefícios da certificação florestal. Revista Floresta, Curitiba, n. esp., p.94-98, 2002.

SILVA, R; BRAVO, M. A. M. P. Comércio exterior e meio ambiente. Revista do BNDES, Rio de Janeiro, v.1, p.113128, 1994.

SUITER FILHO, W. Certificação Florestal: ferramenta para múltiplas soluções. Revista Ação Ambiental, Viçosa, v.3, n.13, p.16-18, 2000.

VENZKE, C. S. A situação do ecodesign em empresas moveleiras da região de Bento Gonçalves, RS: análise da postura e das práticas ambientais. 2002. Dissertação (Mestrado em Administração) - Universidade Federal do Rio Grande do Sul, Porto Alegre. 